\title{
Significant association between IncRNA H19 polymorphisms and cancer susceptibility: a meta-analysis
}

\author{
Xue-Feng Li ${ }^{1, *}$, Xin-Hai Yin ${ }^{2, *}$, Jun-Wei Cai ${ }^{1, *}$, Ming-Ju Wang ${ }^{3}$, Yu-Qin Zeng ${ }^{1}$, Min \\ $\mathrm{Li}^{1}$, Yu-Ming Niu ${ }^{1,4}$ and Ming Shen ${ }^{5}$ \\ ${ }^{1}$ Department of Endocrinology, Taihe Hospital, Hubei University of Medicine, Shiyan 442000, China \\ ${ }^{2}$ Department of Oral and Maxillary Surgery, Gui Zhou Provincial People's Hospital, Guiyang 550000, China \\ ${ }^{3}$ Information Resources, Taihe Hospital, Hubei University of Medicine, Shiyan 442000, China \\ ${ }^{4}$ Department of Stomatology and Center for Evidence-Based Medicine and Clinical Research, Taihe Hospital, Hubei University \\ of Medicine, Shiyan 442000, China \\ 5 Jiangsu Key Laboratory of Oral Diseases, Department of Dental Implant, Affiliated Hospital of Stomatology, Nanjing Medical \\ University, Nanjing 210029, China \\ *These authors contributed equally to this work
}

Correspondence to: Yu-Ming Niu, email: niuyuming@yeah.net Ming Shen, email: mingshen85@yahoo.com

Keywords: H19, polymorphism, cancer, meta-analysis

Received: August 15, $2016 \quad$ Accepted: March 19, $2017 \quad$ Published: March 29, 2017

Copyright: Li et al. This is an open-access article distributed under the terms of the Creative Commons Attribution License 3.0 (CC BY 3.0), which permits unrestricted use, distribution, and reproduction in any medium, provided the original author and source are credited.

\section{ABSTRACT}

Previous epidemiological research suggests polymorphisms in long non-coding RNA (IncRNA) H19 are associated with an increased risk of cancer, but the results are inconsistent. We therefore conducted a meta-analysis to more accurately determine the association between IncRNA H19 polymorphisms and cancer risk. The PubMed, Embase, and Science Citation Index online databases were searched and 11 relevant studies involving a total of 33,209 participants were identified. Odds ratios (ORs) and corresponding $95 \%$ confidence interval (CIs) from these studies were used to detect associations between $\mathrm{H} 19$ polymorphisms and cancer risk using five genetic models. The pooled result suggested that the rs 2839698 G >A polymorphism was associated with digestive cancer risk in all five models. Moreover, a protective effect against cancer development was observed for the T allele variant of the rs2107425 C>T polymorphism, especially in Caucasian patient populations. No significant associations were found between IncRNA H19 rs217727 G>A polymorphism and cancer risk. In summary, the rs2839698 G>A and rs2107425 C>T polymorphisms in IncRNA H19 may therefore play opposing roles during cancer development, and their effects may vary depending on cancer type and patient ethnicity.

\section{INTRODUCTION}

Cancer is a leading cause of death worldwide and has major economic impacts in both developed and developing countries [1, 2]. In 2012, approximately 14.1 million patients were diagnosed with cancer, and 8.2 million people died due to cancer, according to a GLOBOCAN reported [3]. Longer life expectancy, an aging population, and increased environmental pollution may all contribute to increasing incidences of cancer in China and other countries [4]. Other risk factors, such as unhealthy dietary practices and lifestyles, chronic inflammation, and viral infections, also contribute to the development of cancer [5-9]. However, the mechanisms underlying cancer pathogenesis remain largely unknown. Increasing evidence indicates that abnormal gene regulation and expression result in abnormal protein activity and disruption of the cell cycle, in turn leading to tumor formation. Long non-coding RNAs (lncRNAs), which were first identified in the 1990s, are single-stranded, non-coding RNAs with lengths of more than 200 nucleotides and no open reading frames [10]. Molecular studies have shown that lncRNAs play important roles in cell cycle regulation and affect proliferation, differentiation, and apoptosis [11]. LncRNAs are also important regulators of tissue pathology and disease processes related to cancer [12]. 
Thousands of lncRNA molecules have been identified to date in the human genome. The lncRNA H19 is located on chromosome $11 \mathrm{p} 15.5$ and is $2.3 \mathrm{~kb}$ in length [13]. The H19 gene, which is a paternally imprinted onco-fetal gene, is typically down-regulated in adult tissues, but can be expressed in cancer tissues at levels similar to those observed in fetal life [14]. Many studies have confirmed that H19 is re-expressed in many types of solid tumors, such as breast cancer, gastric cancer, and esophageal cancer, and H19 expression is closely related to tumor invasion, metastasis, recurrence and poor prognosis $[15,16]$.

Genetic mutations, such as single nucleotide polymorphisms (SNPs), also influence susceptibility to cancer [17]. Previous studies have also identified associations between cancer risk and SNPs located in lncRNAs; examples include the HOTAIR rs920778 $\mathrm{C}>\mathrm{T}$ polymorphism in esophageal cancer and the PRNCR1 rs13252298 $\mathrm{A}>\mathrm{G}$ polymorphism in gastric cancer [18, 19]. Associations have also been reported between the three most common SNPs in H19 (rs2839698 $\mathrm{G}>\mathrm{A}$, and rs217727 $\mathrm{G}>\mathrm{A}, \mathrm{rs} 2107425 \mathrm{C}>\mathrm{T}$ ) and cancer susceptibility. In 2008, Verhaegh et al. conducted the first case-control study and found that the heterozygote H19 rs2839698 G>A polymorphism might be associated with bladder cancer risk in a Caucasian population [20]. Subsequent studies investigating the association between the lncRNA H19 polymorphisms and cancer susceptibility have reported inconsistent results. Therefore, in this meta-analysis, we examined the association between lncRNA H19 polymorphisms and cancer susceptibility in all relevant published studies. Our meta-analysis was preformed according to the Preferred Reporting Items for Systematic Reviews and Meta-Analyses (PRISMA) statement [21]. No ethical issues were involved in this study given that our data were based on published studies.

\section{RESULTS}

\section{Study characteristics}

A systematic literature search identified 932 potentially relevant articles. At the end of the gradual selection process, eleven published articles involving a total of 14,030 cancer patients and 19,179 healthy controls met our inclusion criteria and were included in this meta-analysis (Figure 1) [20, 22-31]. Among the eleven eligible articles, five studies examined Asian populations, seven examined Caucasian populations and one examined an African populations (one article included two different races, Caucasian and African population). The characteristics of the included studies are presented in Table 1.

\section{Meta-analysis of the IncRNA H19 rs2839698 G $>$ A polymorphism and cancer risk}

The association between the H19 rs2839698 G>A polymorphism and cancer risk was examined in five relevant studies involving 3,369 patients and 3,510 healthy controls. No significant associations were identified between overall cancer risk and this SNP in any of the five genetic models. However, subgroup analyses by cancer type indicated that $\mathrm{rs} 2839698 \mathrm{G}>\mathrm{A}$ was associated with an increase indigestive cancer risk (A vs. G: OR $=1.23$, 95\% CI $=1.10-1.36, P<0.01, I^{2}=0 \%$; GA vs. GG: $\mathrm{OR}=1.17,95 \% \mathrm{CI}=1.02-1.35, P=0.03, I^{2}=0 \%$; AA vs. GG: $\mathrm{OR}=1.58,95 \% \mathrm{CI}=1.22-2.05, P<0.01$, $I^{2}=0 \%$; GA+AA vs. GG: $\mathrm{OR}=1.23,95 \% \mathrm{CI}=1.08-1.41$, $P<0.01, I^{2}=0 \%$; AA vs. GG $+\mathrm{GA}: \mathrm{OR}=1.48,95 \%$ $\mathrm{CI}=1.15-1.90, P<0.01, I^{2}=0 \%$ ) (Table 2). Additional associations were identified in the other subgroup analysis (Table 2, Supplementary Figure 1). Furthermore, metaregression analyses did not reveal any critical factors to explain these heterogeneities, while stratified analyses by cancer type relieved the heterogeneity.

The sensitivity analysis, which was conducted by omitting studies one by one to examine the stability of the pooled ORs, revealed a slight change when data from Li et al.'s study was removed [29] (Supplementary Figure 2). Cumulative analysis by publication date also indicated that the observed dangerous association increased in strength when the same study, which was published in 2016, was included [29] (Supplementary Figure 3).

Potential publication bias was evaluated using Egger's linear regression and Begg's funnel plots. No significant asymmetrical funnel plots were observed, which were guaranteed by the Egger's test (A vs. G: $P=0.77$; GA vs. GG: $P=0.62$; AA vs. GG: $P=0.52$; GA+AA vs. GG: $P=0.62$; AA vs. GG+GA: $P=0.60$ ) (Supplementary Figure 4).

\section{Meta-analysis of the IncRNA H19 rs217727 G>A polymorphism and cancer risk}

The association between lncRNA H19 rs217727 $\mathrm{G}>\mathrm{A}$ polymorphism and cancer risk was examined in five studies involving 3,334 cases and 3,768 controls. No significant overall associations were found in any of the five genetic models (A vs. G: OR $=1.01,95 \% \mathrm{CI}=0.88-1.07$, $P=0.86, I^{2}=72.6 \%$; GA vs. GG: $\mathrm{OR}=0.88,95 \% \mathrm{CI}=0.73-$ $1.06, P=0.18, I^{2}=65.0 \%$; AA vs. GG: OR $=0.60,95 \%$ $\mathrm{CI}=0.26-1.39, P=0.23, I^{2}=16.0 \%$; GA+AA vs. GG: $\mathrm{OR}=0.94,95 \% \mathrm{CI}=0.78-1.12, P=0.47, I^{2}=66.3 \%$; AA vs. $\mathrm{GG}+\mathrm{GA}: \mathrm{OR}=1.19,95 \% \mathrm{CI}=0.93-1.53$, $P=0.16, I^{2}=64.9 \%$ ) (Table 2, Supplementary Figure 5). In contrast, two genetic models (GA vs. GG: $\mathrm{OR}=0.79,95 \% \mathrm{CI}=0.69-0.91, P<0.01, I^{2}=26.6 \%$; $\mathrm{GA}+\mathrm{AA}$ vs. $\mathrm{GG}: \mathrm{OR}=0.82,95 \% \mathrm{CI}=0.72-0.94$, $P<0.01, I^{2}=0 \%$ ) indicated protective effects on cancer risk in population-base subgroup analysis. Additional subgroup analyses based on ethnicity and cancer type did not identify any significant associations. Meta-regression analyses and stratified analyses were also conducted, but no critical factors were found that explain the observed heterogeneities. 
No substantial changes were observed in the sensitivity and cumulative analyses (Supplementary Figures 6 and 7), and no publication bias was observed (A vs. G: $P=0.91$; GA vs. GG: $P=0.70$; AA vs. GG: $P=0.90$; GA+AA vs. GG: $P=0.86$; AA vs. GG+GA: $P=0.79)$ (Supplementary Figure 8).

\section{Meta-analysis of the IncRNA H19 rs2107425 $\mathrm{C}>\mathrm{T}$ polymorphism and cancer risk}

The association between the H19 rs2107425 C>T polymorphism and cancer risk was examined in eight studies involving 10,856 patients and 15,612 healthy controls. A protective effect on cancer development was observed in the variant $\mathrm{T}$ allele (CT vs. $\mathrm{CC}$ : $\mathrm{OR}=0.88$, $95 \% \mathrm{CI}=0.77-1.00, P=0.05, I^{2}=70.4 \%$; $\mathrm{CT}+\mathrm{TT}$ vs. $\mathrm{CC}:$ OR $=0.87 ; 95 \% \mathrm{CI}=0.78-0.97, P=0.02)$. The same association with decreased risk was also observed in Caucasian populations in the subgroup analyses by race $(\mathrm{T}$ vs. $\mathrm{C}$ : $\mathrm{OR}=0.90,95 \% \mathrm{CI}=0.84-0.97$,
$P=0.01, I^{2}=51.8 \%$; CT vs. CC: $\mathrm{OR}=0.82,95 \%$ $\mathrm{CI}=0.72-0.94, P=<0.01, I^{2}=69.1 \%$; CT+TT vs. CC: $\mathrm{OR}=0.83,95 \% \mathrm{CI}=0.75-0.92, P<0.01, I^{2}=62.9 \%$, (Figure 2, Supplementary Figure 9) (Table 2). Metaregression analyses indicated that ethnicity explained the T2 values in these genetic models (T vs. C: $58.7 \%$, $P=0.06$; CT vs. CC: $54.9 \%, P=0.06$; CT + TT vs. CC: $59.8 \%, P=0.03)$.

Sensitivity analysis was conducted by omitting studies one at a time to see whether the pooled ORs were altered, and a slight bias was found when the data from BarnholtzSloan et al.'s study in an African patient population was removed (Figure 3, Supplementary Figure 10). No changes were observed in the cumulative analysis by publication date (Figure 4, Supplementary Figure 11).

Publication bias was evaluated using Egger's linear regression and Begg's funnel plots. No significant asymmetrical funnel plots were observed, which were guaranteed by the Egger's test (T vs. C: $P=0.72$; CT vs. CC: $P=0.88$; TT vs. CC: $P=0.72$, (Figure 5);

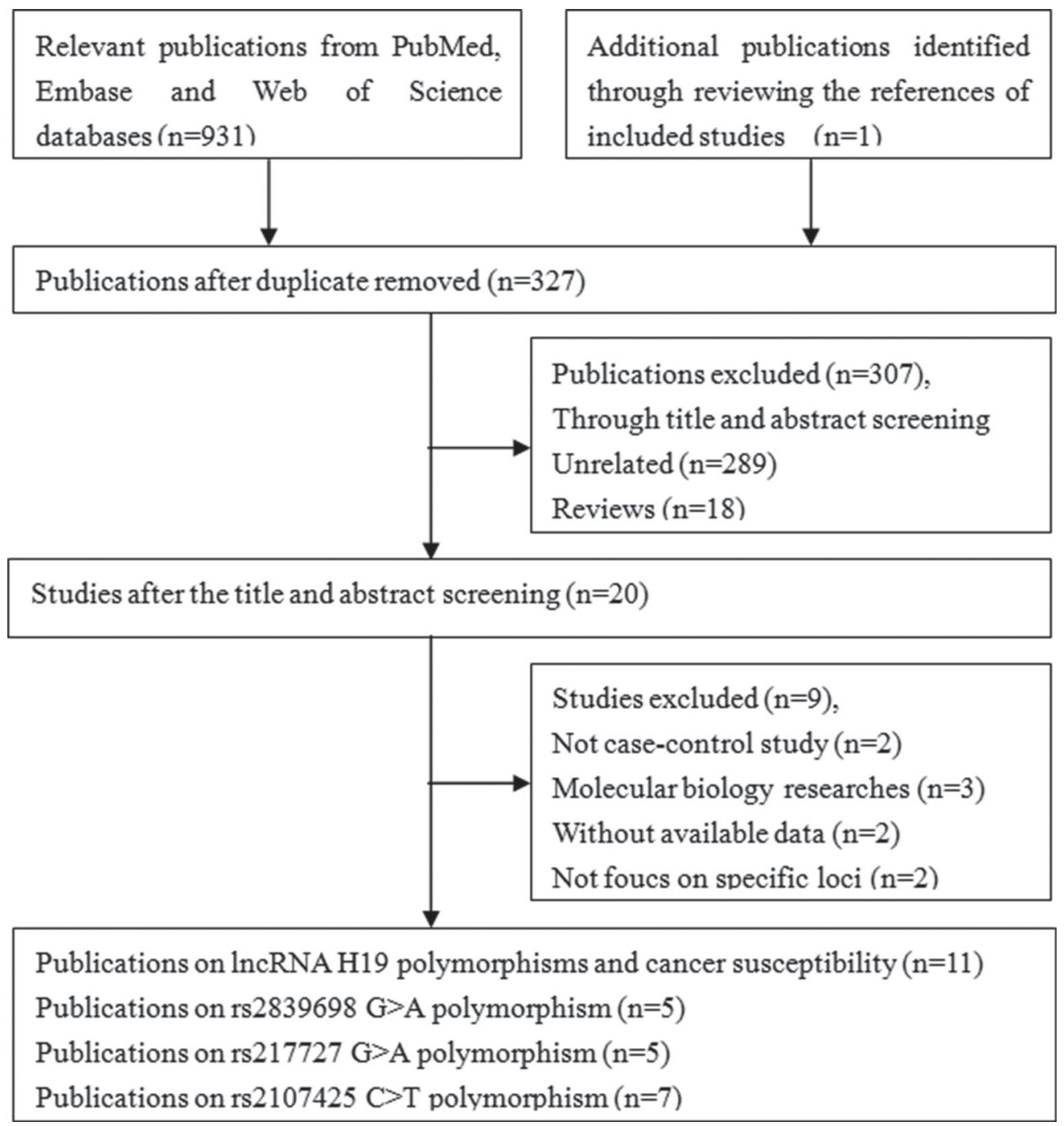

Figure 1: Flow diagram of the study selection process. 
Table 1: Characteristics of included studies on IncRNA H19 polymorphisms and cancer risk included in the meta-analysis

\begin{tabular}{|c|c|c|c|c|c|c|c|c|c|c|c|c|c|c|c|c|c|}
\hline \multirow[b]{2}{*}{ First author } & \multirow[b]{2}{*}{ Year } & \multirow[b]{2}{*}{$\begin{array}{l}\text { Country } \\
\text { /Region }\end{array}$} & \multirow[b]{2}{*}{ Racial } & \multirow[b]{2}{*}{$\begin{array}{c}\text { Source of } \\
\text { controls }\end{array}$} & \multirow[b]{2}{*}{ Case } & \multirow[b]{2}{*}{ Control } & \multicolumn{6}{|c|}{ Genotype distribution } & \multirow[b]{2}{*}{$\begin{array}{c}\text { Genotyping } \\
\text { methods }\end{array}$} & \multirow[b]{2}{*}{$\begin{array}{c}P \text { for } \\
\text { HWE }^{\text {a }}\end{array}$} & \multirow[b]{2}{*}{$\begin{array}{l}\text { MAF in } \\
\text { control }\end{array}$} & \multirow[b]{2}{*}{ Type } & \multirow[b]{2}{*}{ NOS } \\
\hline & & & & & & & \multicolumn{3}{|c|}{ Case } & \multicolumn{3}{|c|}{ Control } & & & & & \\
\hline & & & & & & & \multicolumn{6}{|c|}{ H19 rs2839698 G>A } & & & & & \\
\hline & & & & & & & GG & GA & $\mathbf{A A}$ & GG & GA & $\mathbf{A A}$ & & & & & \\
\hline Verhaegh & 2008 & Netherlands & Caucasian & PB & 177 & 204 & 54 & 74 & 49 & 52 & 109 & 43 & PCR-RFLP & 0.31 & 0.48 & Bladder & 8 \\
\hline Yang & 2015 & China & Asian & HB & 500 & 500 & 250 & 195 & 55 & 284 & 178 & 38 & TaqMan & 0.18 & 0.25 & Gastric & 8 \\
\hline $\mathrm{Li}$ & 2016 & China & Asian & PB & 1147 & 1203 & 583 & 462 & 102 & 666 & 462 & 75 & TaqMan & 0.67 & 0.25 & Colorectal & 9 \\
\hline Hua & 2016 & China & Asian & HB & 1049 & 1397 & 552 & 418 & 79 & 729 & 565 & 103 & TaqMan & 0.65 & 0.28 & Bladder & 9 \\
\hline \multirow[t]{3}{*}{ Gong } & 2016 & China & Asian & $\mathrm{HB}$ & 496 & 206 & 237 & 220 & 39 & 99 & 80 & 27 & TaqMan & 0.10 & 0.33 & Lung & 8 \\
\hline & & & & & & & \multicolumn{6}{|c|}{ H19 rs217727 G>A } & & & & & \\
\hline & & & & & & & GG & GA & $\mathbf{A A}$ & GG & GA & $\mathbf{A A}$ & & & & & \\
\hline Verhaegh & 2008 & Netherlands & Caucasian & PB & 177 & 204 & 114 & 59 & 4 & 115 & 80 & 9 & PCR-RFLP & 0.29 & 0.24 & Bladder & 8 \\
\hline Yang & 2015 & China & Asian & $\mathrm{HB}$ & 500 & 500 & 160 & 252 & 88 & 193 & 244 & 63 & TaqMan & 0.30 & 0.37 & Gastric & 8 \\
\hline $\mathrm{Li}$ & 2016 & China & Asian & PB & 1147 & 1203 & 480 & 514 & 153 & 456 & 570 & 177 & TaqMan & 0.96 & 0.38 & Colorectal & 9 \\
\hline Hua & 2016 & China & Asian & HB & 1046 & 1394 & 431 & 467 & 148 & 573 & 665 & 156 & TaqMan & 0.07 & 0.35 & Bladder & 9 \\
\hline \multirow[t]{3}{*}{ Xia } & 2016 & China & Asian & PB & 464 & 467 & 160 & 156 & 148 & 139 & 212 & 116 & CRS-RFLP & 0.05 & 0.48 & Breast & 10 \\
\hline & & & & & & & \multicolumn{6}{|c|}{ H19 rs2107425 C $>$ T } & & & & & \\
\hline & & & & & & & $\mathrm{CC}$ & CT & TT & $\mathrm{CC}$ & CT & TT & & & & & \\
\hline Verhaegh & 2008 & Netherlands & Caucasian & PB & 177 & 204 & 92 & 65 & 20 & 89 & 96 & 19 & PCR-RFLP & 0.34 & 0.33 & Bladder & 8 \\
\hline Bhatti & 2008 & USA & Caucasian & PB & 824 & 1073 & 392 & & & 502 & 57 & & Sequenom & NA & NA & Breast & 6 \\
\hline Quay & 2009 & Mixed & Caucasian & PB & 1460 & 2463 & 767 & 544 & 149 & 1118 & 1098 & 247 & TaqMan & 0.34 & 0.32 & Ovarian & 8 \\
\hline Song & 2009 & Mixed & Caucasian & PB & 5366 & 8538 & 2619 & 2192 & 555 & 4029 & 3667 & 842 & TaqMan & 0.86 & 0.31 & Ovarian & 9 \\
\hline Butt & 2012 & Sweden & Caucasian & PB & 678 & 1355 & 360 & 250 & 68 & 637 & 573 & 145 & MassArray & 0.34 & 0.32 & Breast & 8 \\
\hline $\begin{array}{l}\text { Barnholtz- } \\
\text { Sloan11 }\end{array}$ & 2014 & USA & Caucasian & PB & 1225 & 1118 & 604 & 516 & 105 & 521 & 478 & 119 & Illumina & 0.55 & 0.32 & Breast & 10 \\
\hline $\begin{array}{l}\text { Barnholtz- } \\
\text { Sloan12 }\end{array}$ & 2014 & USA & Africa & PB & 737 & 658 & 161 & 390 & 186 & 170 & 339 & 149 & Illumina & 0.42 & 0.48 & Breast & 10 \\
\hline Gong & 2016 & China & Asian & HB & 479 & 203 & 181 & 235 & 63 & 79 & 96 & 28 & TaqMan & 0.89 & 0.37 & Lung & 8 \\
\hline
\end{tabular}

aHWE in control

MAF: Minor allele frequency in control group.

PB: Population-based HB: Hospital-based.

CRS-RFLP: Created restriction site-restriction fragment length polymorphism. 
Table 2: Summary ORs and 95\% CI of IncRNA H19 polymorphisms and cancer risk

\begin{tabular}{|c|c|c|c|c|c|c|c|c|c|c|c|c|c|c|c|c|c|c|c|c|c|c|}
\hline Locus & $N^{*}$ & $\begin{array}{l}\text { No. of case/ } \\
\text { control }\end{array}$ & $\mathrm{OR}$ & $95 \% \mathrm{CI}$ & $P$ & $\begin{array}{c}F^{2} \\
(\%)^{n}\end{array}$ & $\mathrm{OR}$ & $95 \%$ CI & $P$ & $f^{2}(\%)^{\mathrm{a}}$ & OR & $95 \% \mathrm{CI}$ & $P$ & $\begin{array}{c}P^{2} \\
(\%)^{a}\end{array}$ & OR & $95 \% \mathrm{CI}$ & $P$ & $\begin{array}{c}F^{2} \\
(\%)^{\mathrm{a}}\end{array}$ & OR & $95 \%$ CI & $P$ & $\begin{array}{c}F^{2} \\
(\%)^{n}\end{array}$ \\
\hline $\mathrm{rs} 2839698 \mathrm{G}>\mathrm{A}$ & & & \multicolumn{4}{|c|}{ A vs. G } & \multicolumn{4}{|c|}{ GAvs. GG } & \multicolumn{4}{|c|}{ AA vs. GG } & \multicolumn{4}{|c|}{ GA+AA vs. GG } & \multicolumn{4}{|c|}{ AA vs. $\mathbf{G G}+\mathbf{G A}$} \\
\hline Total & 5 & $3369 / 3510$ & 1.08 & $0.96-1.23$ & 0.21 & 58.8 & 1.06 & $0.91-1.23$ & 0.44 & 43.8 & 1.15 & $0.83-1.58$ & 0.42 & 66.1 & 1.08 & $0.94-1.25$ & 0.27 & 46.5 & 1.15 & $1.85-1.57$ & 0.36 & 67.4 \\
\hline \multicolumn{23}{|l|}{ Ethnicity } \\
\hline Asian & 4 & $3192 / 3306$ & 1.09 & $0.94-1.27$ & 0.24 & 68.6 & 1.09 & $0.98-1.21$ & 0.10 & 0 & 1.15 & $0.78-1.69$ & 0.48 & 74.4 & 1.12 & $0.97-1.28$ & 0.11 & 42.3 & 1.10 & $0.76-1.59$ & 0.63 & 74.0 \\
\hline \multicolumn{23}{|l|}{ Design } \\
\hline PB & 2 & $1324 / 1407$ & 1.17 & $1.04-1.31$ & 0.01 & 0 & 0.91 & $0.53-1.55$ & 0.72 & 78.2 & 1.43 & $1.08-1.88$ & 0.01 & 10.9 & 1.02 & $0.68-1.54$ & 0.93 & 68.2 & 1.46 & $1.13-1.89$ & $<0.01$ & 0 \\
\hline $\mathrm{HB}$ & 3 & $2045 / 2103$ & 1.05 & $0.86-1.28$ & 0.63 & 69.8 & 1.08 & $0.92-1.26$ & 0.36 & 20.6 & 1.02 & $0.62-1.67$ & 0.93 & 74.7 & 1.08 & $0.90-1.31$ & 0.40 & 47.6 & 0.98 & $0.61-1.57$ & 0.92 & 75.0 \\
\hline \multicolumn{23}{|l|}{ Type } \\
\hline Bladder cancer & 2 & $1226 / 1601$ & 1.00 & $0.89-1.12$ & 1.00 & 0 & 0.85 & $0.59-1.24$ & 0.41 & 58.0 & 1.03 & $0.79-1.36$ & 0.82 & 0 & 0.96 & $0.82-1.11$ & 0.57 & 0 & 1.13 & $0.88-1.46$ & 0.35 & 28.0 \\
\hline Digestive cancer & 2 & $1647 / 1703$ & 1.23 & $1.10-1.36$ & $<0.01$ & 0 & 1.17 & $1.02-1.35$ & 0.03 & 0 & 1.58 & $1.22-2.05$ & $<0.01$ & 0 & 1.23 & $1.08-1.41$ & $<0.01$ & 0 & 1.48 & $1.15-1.90$ & $<0.01$ & 0 \\
\hline $\mathrm{rs} 217727 \mathrm{G}>\mathrm{A}$ & & & \multicolumn{4}{|c|}{ A vs. G } & \multicolumn{4}{|c|}{ GA vs. GG } & \multicolumn{4}{|c|}{ AA vs. GG } & \multicolumn{4}{|c|}{ GA+AA vs. GG } & \multicolumn{4}{|c|}{ AA vs. $\mathbf{G G}+\mathbf{G A}$} \\
\hline Total & 5 & $3334 / 3768$ & 1.01 & $0.88-1.07$ & 0.86 & 72.6 & 0.88 & $0.73-1.06$ & 0.18 & & 0.60 & $0.26-1.39$ & 0.23 & 16.0 & 0.94 & $0.78-1.12$ & 0.47 & 66.3 & 1.19 & $0.93-1.53$ & 0.16 & 64.9 \\
\hline \multicolumn{23}{|l|}{ Ethnicity } \\
\hline Asian & 4 & $3157 / 3564$ & 1.05 & $0.91-1.21$ & 0.49 & 73.6 & 0.90 & $0.73-1.11$ & 0.32 & & 0.50 & $0.20-1.25$ & 0.14 & 23.3 & 0.97 & $0.80-1.17$ & 0.76 & 70.3 & 1.23 & $0.97-1.57$ & 0.09 & 68.0 \\
\hline \multicolumn{23}{|l|}{ Design } \\
\hline PB & 3 & $1788 / 1874$ & 0.92 & $0.84-1.01$ & 0.09 & 46.6 & 0.79 & $0.69-0.91$ & $<0.01$ & & 1.07 & $0.36-3.22$ & 0.90 & 0 & 0.82 & $0.72-0.94$ & $<0.01$ & 0 & 1.03 & $0.66-1.58$ & 0.91 & 73.5 \\
\hline $\mathrm{HB}$ & 2 & $1546 / 1894$ & 1.15 & $0.97-1.37$ & 0.12 & 62.9 & 1.06 & $0.80-1.40$ & 0.70 & & 0.26 & $0.06-1.20$ & 0.08 & 31.5 & 1.13 & $0.85-1.51$ & 0.39 & 71.6 & 1.36 & $1.12-1.66$ & $<0.01$ & 0 \\
\hline \multicolumn{23}{|l|}{ Type } \\
\hline Bladder cancer & 2 & $1223 / 1598$ & 0.92 & $0.65-1.31$ & 0.65 & 73.4 & 0.90 & $0.77-1.06$ & 0.22 & 0 & 0.51 & $0.04-6.77$ & 0.61 & 62.5 & 0.89 & $0.66-1.21$ & 0.47 & 53.5 & 0.97 & $0.41-2.32$ & 0.95 & 58.0 \\
\hline Digestive cancer & 2 & $1647 / 1703$ & 1.06 & $0.75-1.50$ & 0.75 & 90.5 & 1.02 & $0.71-1.47$ & 0.93 & 80.4 & 0.52 & $0.10-2.81$ & 0.45 & 0 & 1.05 & $0.67-1.64$ & 0.82 & 88.0 & 1.13 & $0.69-1.85$ & 0.63 & 82.1 \\
\hline $\mathrm{rs} 2107425 \mathrm{C}>\mathrm{T}$ & & & Tvs. C & & & & CT vs. CC & & & & TT vs. CC & & & & $\mathrm{CT}+\mathrm{TT}$ vs. $\mathrm{Cl}$ & & & & vs. $\mathrm{CC}-$ & & & \\
\hline Total & 8 & $10946 / 15612$ & 0.94 & $0.86-1.01$ & 0.09 & 60.8 & 0.88 & $0.77-1.00$ & 0.05 & 70.4 & 0.97 & $0.89-1.06$ & 0.51 & 32.4 & 0.87 & $0.78-0.97$ & 0.02 & 68.4 & 1.02 & $0.94-1.11$ & 0.60 & 0 \\
\hline \multicolumn{23}{|l|}{ Ethnicity } \\
\hline Caucasian & 6 & $9730 / 14751$ & 0.90 & $0.84-0.97$ & 0.01 & 51.8 & 0.82 & $0.72-0.94$ & $<0.01$ & 69.1 & 0.94 & $0.86-1.04$ & 0.22 & 13.9 & 0.83 & $0.75-0.92$ & $<0.01$ & 62.9 & 1.01 & $0.92-1.10$ & 0.85 & 8.1 \\
\hline \multicolumn{23}{|l|}{ Design } \\
\hline PB & 7 & $10467 / 15409$ & 0.93 & $0.85-1.01$ & 0.09 & 66.7 & 0.86 & $0.75-0.99$ & 0.03 & 73.9 & 0.95 & $0.83-1.10$ & 0.50 & 43.6 & 0.86 & $0.77-0.97$ & 0.01 & 71.7 & 1.02 & $0.94-1.11$ & 0.57 & 6.5 \\
\hline \multicolumn{23}{|l|}{ Type } \\
\hline breast cancer & 4 & $3464 / 4204$ & 0.95 & $0.80-1.13$ & 0.57 & 77.7 & 0.94 & $0.75-1.19$ & 0.62 & $73.2 \%$ & 0.94 & $0.67-1.31$ & 0.72 & 73.0 & 0.89 & $0.74-1.08$ & 0.24 & 73.3 & 0.95 & $0.76-1.20$ & 0.68 & 51.8 \\
\hline Ovarian cancer & 2 & $6826 / 11001$ & 0.92 & $0.80-1.05$ & 0.20 & 82.5 & 0.82 & $0.65-1.05$ & 0.10 & 89.2 & 0.98 & $0.89-1.09$ & 0.74 & 18.4 & 0.84 & $0.68-1.05$ & 0.13 & 88.6 & 1.05 & $0.95-1.16$ & 0.37 & 0.0 \\
\hline
\end{tabular}

Numbers of comparisons.

"Test for heterogeneity.

PB: Population-based HB: Hospital-based.

RT-PCR: Real-time PCR.

CT+TT vs. CC: $P=0.71$; TT vs. CC+CT: $P=0.59)$

(Supplementary Figure 12).

\section{DISCUSSION}

Cancer is currently a main cause of poverty and death worldwide. However, the fundamental mechanism of the pathogenesis of cancer remains unclear. Noncoding RNAs, including lncRNAs, affect many cellular processes by regulating gene function and maintaining cellular homeostasis, both of which are closely related to organ differentiation and disease development [32, 33]. Abnormal expression of lncRNAs is closely linked to the occurrence, development and postoperative recovery from cancer; thus, lncRNAs are likely to be useful diagnostic and prognostic markers and might also serve as targets for IncRNA-mediated therapies [34].

Large numbers of SNP loci have been identified in many lncRNAs, and an increasing number of studies have focused on the association between lncRNA polymorphisms and cancer risk. LncRNAs are approximately 200 nucleotide long RNA molecules that are stably expressed in plasma but do not code for proteins. Accumulating evidence has demonstrated that abnormal expressions of lncRNAs are often promotes tumorigenesis through by interfering with normal cell cycle progression [35]. The H19 gene belong to a highly conserved imprinted gene that affects embryonic development and growth [36]. Recent studies have demonstrated that lncRNA H19 plays important roles in carcinogenesis and cancer metastasis. For example, Luo et al found that up-regulated $\mathrm{H} 19$ enhances bladder cancer metastasis with EZH2 and inhibiting E-cad expression [16]. In addition, Han et al also found that increased H19 expression was associated with tumor grade and TNM stage in colorectal cancer patients [37]. Furthermore, growing evidences suggests that polymorphisms in the H19 gene affect cancer development. In 2008, H19 polymorphisms were first examined by Verhaegh et al. [20], and a series of case-control studies have since been conducted. However, additional studies are needed to confirm those results due to the limited number of studies and small sample sizes involved.

Meta-analysis can be used to integrate data from multiple studies, thereby expanding sample sizes and increasing the strength of conclusions [38]. We conducted 


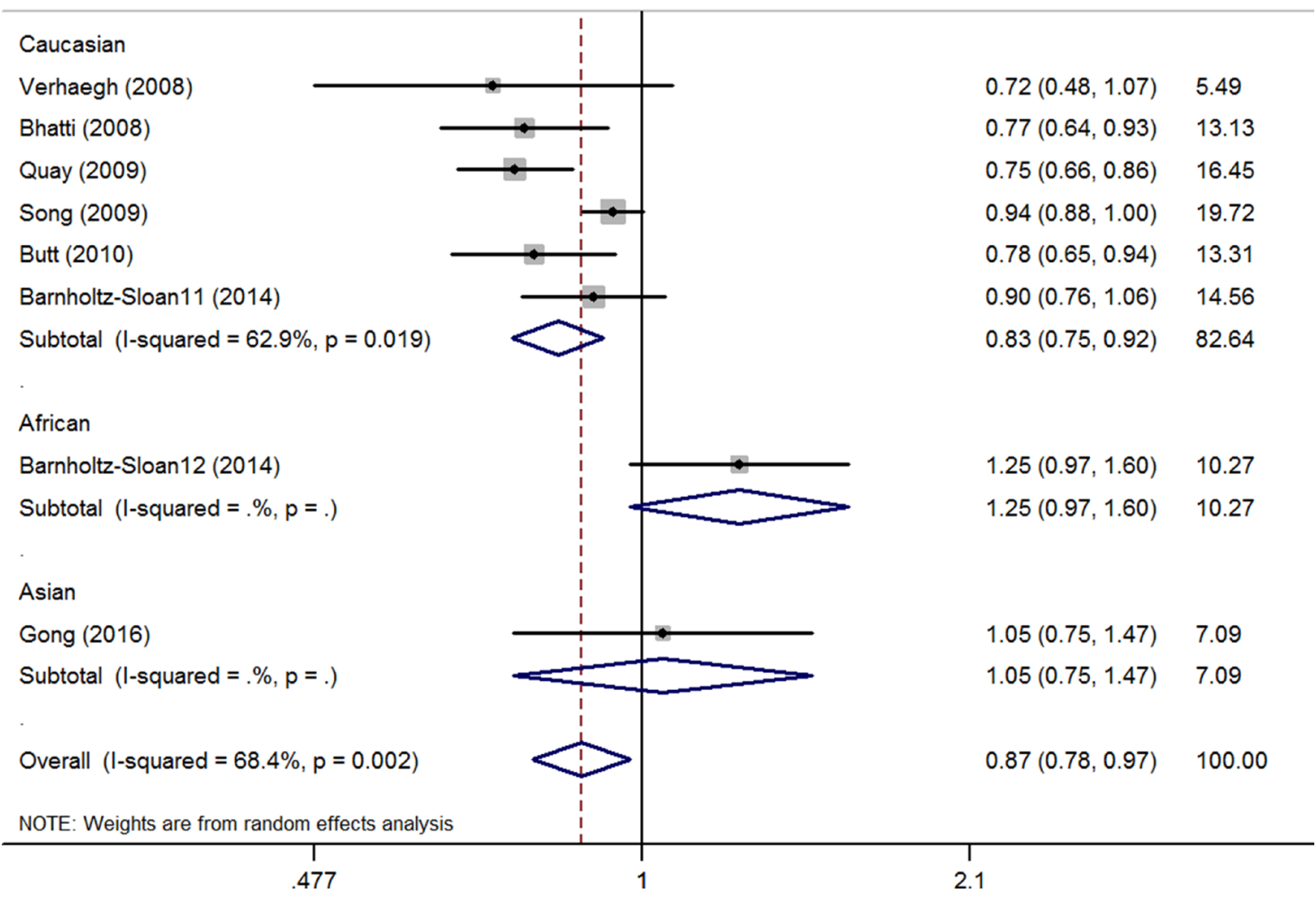

Figure 2: OR and 95\% CIs of the associations between IncRNA H19 rs2107425 C $>$ T polymorphism and cancer risk in CT+TT vs. CC model.

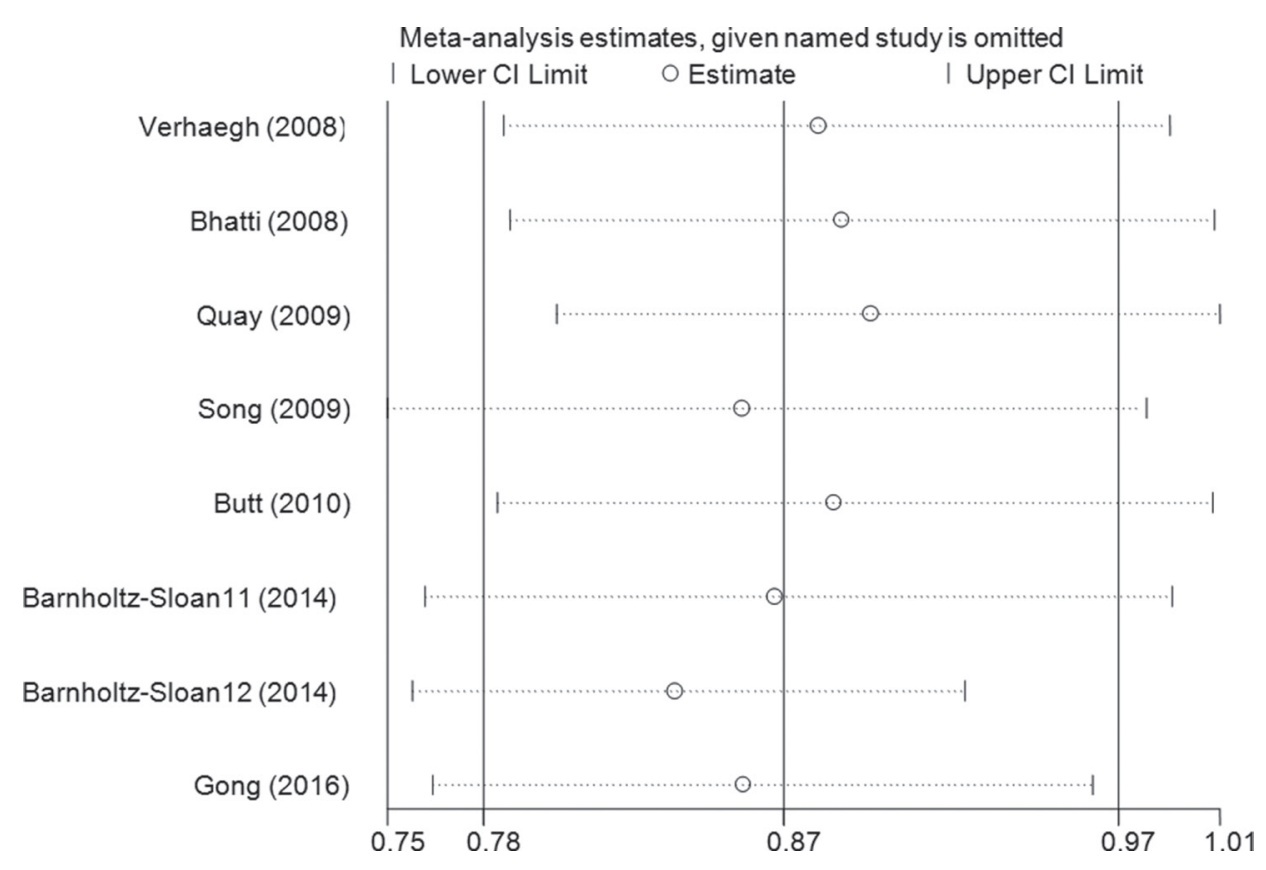

Figure 3: Sensitivity analysis through deleting each study to reflect the influence of the individual dataset to the pooled ORs between IncRNA H19 rs2107425 C $>$ T polymorphism and cancer risk in CT+TT vs. CC model. 
Verhaegh (2008)

Bhatti (2008)

Quay (2009)

Song (2009)

Butt (2010)

Barnholtz-Sloan11 (2014)

Barnholtz-Sloan12 (2014)

Gong (2016)

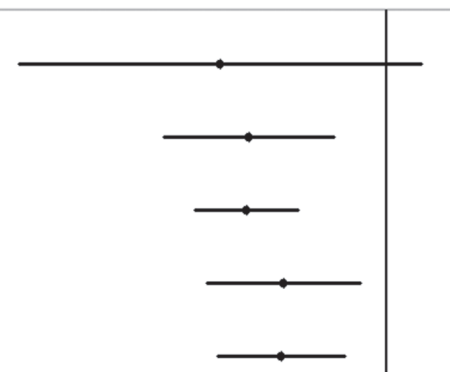

$0.72(0.48,1.07)$

$0.76(0.64,0.90)$

$0.75(0.68,0.84)$

$0.81(0.70,0.95)$

$0.81(0.71,0.92)$

$0.83(0.75,0.92)$

$0.86(0.77,0.97)$

$0.87(0.78,0.97)$

\section{.477}

1

2.1

Figure 4: Cumulative meta-analyses according to publication year between IncRNA H19 rs2107425 C $>$ T polymorphism and cancer risk in $\mathrm{CT}+\mathrm{TT}$ vs. $\mathrm{CC}$ model.

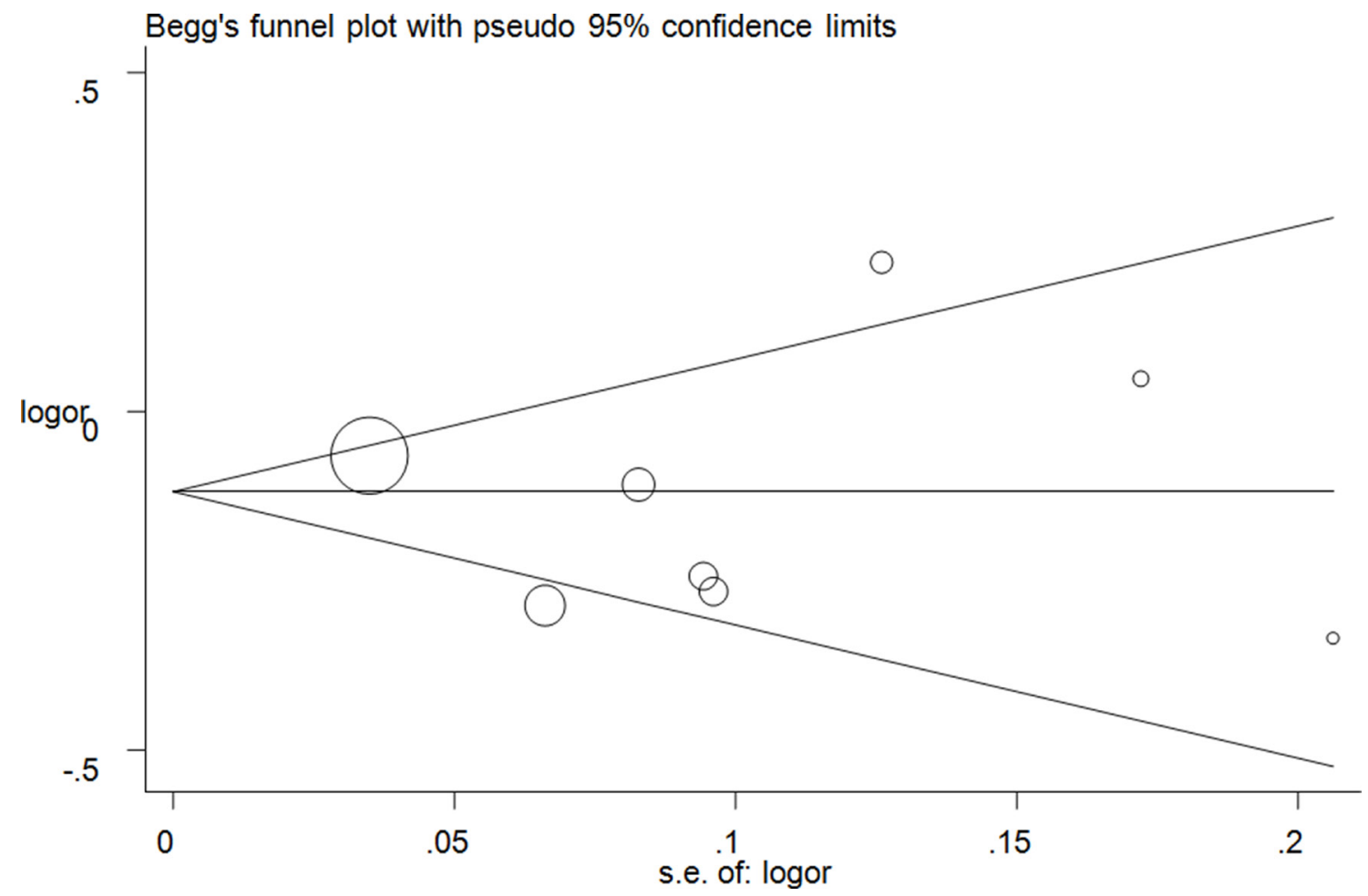

Figure 5: Funnel plot analysis of the publication bias of IncRNA H19 rs2107425 C $>$ T polymorphism and cancer risk in CT+TT vs. CC model. Circles represent the weight of the studies. 
this meta-analysis of eleven studies to more accurately assess the associations between the lncRNA H19 polymorphisms rs2839698 $\mathrm{G}>\mathrm{A}$, rs217727 $\mathrm{G}>\mathrm{A}$ and rs2107425 $\mathrm{C}>\mathrm{T}$ polymorphisms and cancer risk. Our results revealed that the lncRNA H19 rs2839698 $\mathrm{G}>\mathrm{A}$ polymorphism might be an important risk factor for developing gastric cancer and colorectal cancer. In contrast, the $\mathrm{T}$ allele variant of the lncRNA H19 rs2107425 $\mathrm{C}>\mathrm{T}$ polymorphism had a protective effect against cancer development, especially in Caucasian population. Stratified analyses suggested that differences in cancer location and patient ethnicity might have contributed to discrepancies among the studies examined. The lack of significant deviations in the sensitivity and publication bias analyses indicated that the pooled results were stable and credible. In 2016, Lu et al. conducted the first meta-analysis of the association between a singleH19 polymorphism locus (rs217727) and cancer risk in four studies. Their results indicated that this polymorphism was not associated with overall cancer risk [39]. In addition, Chu et al. carried out another meta-analysis assessing the association between $\mathrm{H} 19$ rs2839698 G>A, rs217727 $\mathrm{G}>\mathrm{A}$ and $\mathrm{rs} 2107425 \mathrm{C}>\mathrm{T}$ polymorphisms and cancer risk through aggregating ten published articles [40]. They suggested that the rs2107425 $\mathrm{C}>\mathrm{T}$ polymorphism correlated with a significantly decreased risk but the rs2839698 $\mathrm{G}>\mathrm{A}$ polymorphism exhibited a significantly higher risk of developing cancer. Compared with the previous meta-analysis, our meta-analysis used more scientific retrieval strategy and our meta-analysis collected more research subjects (eleven published studies involving 33,209 participants). Furthermore, our metaanalysis performed the quality evaluation with modified Newcastle-Ottawa scale (NOS), which could make a correct evaluation of the quality of the included studies. In addition, meta-regression was also conducted to explore the causes of heterogeneity during our analysis.

To the best of our knowledge, this is the first metaanalysis to examine the association between these three lncRNA H19 polymorphisms and the risk of different types of cancer. Although only eleven studies involving relatively small sample sizes of 14,030 cases and 19,179 controls were included, these results help to characterize associations between lncRNA H19 polymorphisms and cancer risk. Our conclusions are further supported by the observation that genotype distributions of the selected SNP loci in the healthy controls were consistent with HWE and by the lack of any significant publication bias. However, due to the relatively small number of studies included and to limitations of the linear regression method employed, additional studies should be conducted to confirm these results and reduce the effects of possible publication biases.

Some additional limitations of this meta-analysis should be considered when interpreting the results. First, only eleven studies involving the three SNP loci examined were identified; the small number sizes might decrease the reliability of the results and increases the probability of random errors, thus affecting the assessment of associations between these lncRNA H19 polymorphisms and cancer susceptibility. Second, some important patient characteristics, such as cigarette use and alcohol consumption, as well as other environmental factors, were not considered. The impact of interactions between genetic and environmental factors on cancer development could not be assessed in this study. Third, all of the included studies focused almost exclusively on Asian or Caucasian populations, and our results may not be applicable to all populations. Fourth, the lncRNA H19 rs2839698 G>A, rs217727 G>A and rs2107425 $\mathrm{C}>\mathrm{T}$ polymorphisms were analyzed separately, and the effects of haplotype and gene-gene interactions could not be analyzed with the available data. Fifth, heterogeneity existed in all three polymorphism loci. Clinical diversity (sometimes called clinical heterogeneity), methodological diversity (methodological heterogeneity) and statistical heterogeneity were the most common source. In our metaanalysis, many factors such as the diversity of cancer type, classification of disease severity, environment factors, might have increased heterogeneity and influenced our findings.

Despite these limitations, our meta-analysis indicated that the lncRNA lncRNA H19 rs2839698 G>A and rs $2107425 \mathrm{C}>\mathrm{T}$ polymorphisms might play different role during cancer development. More studies in patients of different ethnicities and with larger number sizes are needed to confirm these findings.

\section{MATERIALS AND METHODS}

\section{Search strategy}

Two of the authors independently searched the online PubMed, Embase, and Science Citation Index (SCI) English databases for relevant studies published prior to December 1, 2016 that examined associations between H19 lncRNA polymorphisms and cancer risk. The bibliographies of relevant studies and recently reviews were retrospectively examined to identify additional articles. The following search terms and strategy were used:

\#1 lncRNA H19

\#2 long non-coding RNA H19

\#3 H19

\#4 rs2839698

\#5 rs2107425

\#6 rs217727

\#7 \#1 OR \#2 OR \#3 OR \#4 OR \#5 OR \#6

\#8 polymorphism

\#9 variant

\#10 mutation

\#11 \#8 OR \#9 OR \#10 
Table 3: Scale for quality evaluation

\begin{tabular}{|c|c|}
\hline Criteria & Score \\
\hline \multicolumn{2}{|l|}{ Representativeness of cases } \\
\hline $\begin{array}{l}\text { Consecutive/randomly selected form case population with } \\
\text { clearly defined sampling frame }\end{array}$ & 2 \\
\hline $\begin{array}{l}\text { Consecutive/randomly selected form case population without } \\
\text { clearly defined sampling frame or with extensive }\end{array}$ & 1 \\
\hline Not described & 0 \\
\hline \multicolumn{2}{|l|}{ Source of controls } \\
\hline Population- or Healthy-based & 2 \\
\hline Hospital-bases & 1 \\
\hline Not described & 0 \\
\hline \multicolumn{2}{|l|}{ Hardy-Weinberg equilibrium in controls } \\
\hline Hardy-Weinberg equilibrium & 2 \\
\hline Hardy-Weinberg disequilibrium & 1 \\
\hline Not available & 0 \\
\hline \multicolumn{2}{|l|}{ Genotyping examination } \\
\hline $\begin{array}{l}\text { Genotyping done under "blinded" condition and repeated } \\
\text { again }\end{array}$ & 2 \\
\hline Genotyping done under "blinded" condition or repeated again & 1 \\
\hline Unblinded done or not mentioned and unrepeated & 0 \\
\hline \multicolumn{2}{|l|}{ Association assessment } \\
\hline $\begin{array}{l}\text { Assess association between genotypes and cancer with } \\
\text { appropriate statistics and adjustment for confounders }\end{array}$ & 2 \\
\hline $\begin{array}{l}\text { Assess association between genotypes and cancer with } \\
\text { appropriate statistics and without adjustment for confounders }\end{array}$ & 1 \\
\hline Inappropriate statistics used & 0 \\
\hline
\end{tabular}

\#12 cancer

\#13 tumor

\#14 neoplasm

\#15 \#12 OR \#13 OR \#14

\#16 \#7 AND \#11 AND \#15

\section{Eligibility criteria}

Studies were collected according to the following inclusion criteria: 1) case-control studies focused on the association between lncRNA H19 polymorphisms and cancer risk; 2) genotype distribution and frequency data provided were sufficient to estimate the odds ratios (ORs) and $95 \%$ confidence intervals (CIs); 3 ) studies published only in English; and 4) data for the largest sample set or most recent samples were included when data from the same set of patients were used more than once within a study.

\section{Data extraction and quality evaluation}

Two investigators ( $\mathrm{Li}$ and Yin) independently extracted the following relevant information from the included studies: abbreviated name of the first author, publishing date, country or region where the study was conducted, patient ethnicity (Asian/Caucasian), the design of the controls, sample sizes for patients and healthy controls, genotype distribution frequency data, genotyping method, Hardy-Weinberg equilibrium (HWE) for the controls, and cancer type. Quality evaluation of included studies was assessed by the first two authors using modified Newcastle-Ottawa scale (NOS), the scores ranged from 0 points (worst) to 10 points (best) (Table 3 ).

\section{Statistical analysis}

Crude ORs with 95\% CIs were calculated to assess the strength between IncRNA H19 rs2839698 G>A, rs217727 $\mathrm{G}>\mathrm{A}$ and $\mathrm{rs} 2107425 \mathrm{C}>\mathrm{T}$ polymorphisms and cancer susceptibility. For the lncRNA H19 rs2839698 $\mathrm{G}>\mathrm{A}$ polymorphism, the following five genetic models were used: allele contrast (A vs. G), co-dominant models (GA vs. GG and AA vs. GG), dominant model (GA+AA vs. GG), and recessive model (AA vs. GG+GA). Similar genetic models were also used to assess the lncRNA H19 rs217727 $\mathrm{G}>\mathrm{A}$ and rs2107425 $\mathrm{C}>\mathrm{T}$ polymorphisms. Stratified measurements were calculated based on ethnicity difference, HWE status, control design, and so on. Heterogeneity was calculated using Cochran's $Q$ test and $I^{2}$ statistic[41]. The fixed-effect model (the Mantel-Haenszel method) was adopted when the $\mathrm{I}^{2}$ value less than $50 \%[42]$. Otherwise, a random-effects model (DerSimonian and Laird method) was applied [43, 44]. Meta-regression was conducted to examine analyses that exhibited heterogeneity. Cumulative meta-analyses were conducted to determine 
whether the results changed significantly as the number of studies included increased. Furthermore, sensitivity analyses were also performed to examine the stability of the results when studies were removed one at a time. Both Egger's linear regression and Begg's funnel plots were used to assess the potential publication bias [45, 46]. All statistical calculations were performed with STATA version 14.0 (Stata Corporation, College Station, TX, USA). A $P$ value $<0.05$ was considered statistically significant.

\section{ACKNOWLEDGMENTS AND FUNDING}

We thank professor Zhao-Qian Liu, Wei-Jing Gong and Xi Li (Department of Clinical Pharmacology, Xiangya Hospital, and Central South University) provide experimental data. This study was supported by the Foundations of the Science and Technology Department of Hubei Province (No. 2016CFB567) and Hubei Province health and family planning scientific research project (No. WJ2017F069). The funders had no roles in study design, data collection and analysis, decision to publish, or preparation of the manuscript.

\section{CONFLICTS OF INTEREST}

The authors declare no competing financial interest.

\section{REFERENCES}

1. Siegel RL, Miller KD, Jemal A. Cancer statistics, 2015. CA Cancer J Clin. 2015; 65:5-29.

2. Ferlay J, Shin HR, Bray F, Forman D, Mathers C, Parkin DM. Estimates of worldwide burden of cancer in 2008: GLOBOCAN 2008. Int J Cancer. 2010; 127:2893-2917.

3. Torre LA, Bray F, Siegel RL, Ferlay J, Lortet-Tieulent J, Jemal A. Global cancer statistics, 2012. CA Cancer J Clin. 2015; 65:87-108.

4. Chen W, Zheng R, Baade PD, Zhang S, Zeng H, Bray F, Jemal A, Yu XQ, He J. Cancer statistics in China, 2015. CA Cancer J Clin. 2016; 66:115-132.

5. Alnuaimi AD, Wiesenfeld D, O'Brien-Simpson NM, Reynolds EC, McCullough MJ. Oral Candida colonization in oral cancer patients and its relationship with traditional risk factors of oral cancer: a matched case-control study. Oral Oncol. 2015; 51:139-145.

6. Khawar MB, Abbasi MH, Sheikh N. IL-32: A Novel Pluripotent Inflammatory Interleukin, towards Gastric Inflammation, Gastric Cancer, and Chronic Rhino Sinusitis. Mediators Inflamm. 2016; 2016:8413768.

7. Wang CC, Palefsky JM. Human papillomavirus-related oropharyngeal cancer in the HIV-infected population. Oral Dis. 2016; 22:98-106.

8. Tornesello ML, Buonaguro L, Izzo F, Buonaguro FM. Molecular alterations in hepatocellular carcinoma associated with hepatitis B and hepatitis C infections. Oncotarget. 2016; 7:25087-102. doi: 10.18632/oncotarget.7837.
9. Girschik J, Heyworth J, Fritschi L. Self-reported sleep duration, sleep quality, and breast cancer risk in a population-based casecontrol study. Am J Epidemiol. 2013; 177:316-327.

10. Chen G, Wang Z, Wang D, Qiu C, Liu M, Chen X, Zhang Q, Yan G, Cui Q. LncRNADisease: a database for long-noncoding RNA-associated diseases. Nucleic Acids Res. 2013; 41:D983-986.

11. Bhan A, Mandal SS. Long noncoding RNAs: emerging stars in gene regulation, epigenetics and human disease. ChemMedChem. 2014; 9:1932-1956.

12. Iyer MK, Niknafs YS, Malik R, Singhal U, Sahu A, Hosono Y, Barrette TR, Prensner JR, Evans JR, Zhao S, Poliakov A, Cao X, Dhanasekaran SM, et al. The landscape of long noncoding RNAs in the human transcriptome. Nat Genet. 2015; 47:199-208.

13. Brannan CI, Dees EC, Ingram RS, Tilghman SM. The product of the H19 gene may function as an RNA. Mol Cell Biol. 1990; 10:28-36.

14. Ohana P, Kopf E, Bibi O, Ayesh S, Schneider T, Laster M, Tykocinski M, de Groot N, Hochberg A. The expression of the $\mathrm{H} 19$ gene and its function in human bladder carcinoma cell lines. FEBS Lett. 1999; 454:81-84.

15. Matouk IJ, Raveh E, Abu-lail R, Mezan S, Gilon M, Gershtain E, Birman T, Gallula J, Schneider T, Barkali M, Richler C, Fellig Y, Sorin V, et al. Oncofetal H19 RNA promotes tumor metastasis. Biochim Biophys Acta. 2014; 1843:1414-1426.

16. Luo M, Li Z, Wang W, Zeng Y, Liu Z, Qiu J. Long noncoding RNA H19 increases bladder cancer metastasis by associating with EZH2 and inhibiting E-cadherin expression. Cancer Lett. 2013; 333:213-221.

17. Niu YM, Du XY, Lu MY, Xu QL, Luo J, Shen M. Significant association between functional microRNA polymorphisms and head and neck cancer susceptibility: a comprehensive meta-analysis. Sci Rep. 2015; 5:12972.

18. Zhang X, Zhou L, Fu G, Sun F, Shi J, Wei J, Lu C, Zhou C, Yuan Q, Yang M. The identification of an ESCC susceptibility SNP rs920778 that regulates the expression of IncRNA HOTAIR via a novel intronic enhancer. Carcinogenesis. 2014; 35:2062-2067.

19. Li L, Jia F, Bai P, Liang Y, Sun R, Yuan F, Zhang L, Gao L. Association between polymorphisms in long non-coding RNA PRNCR1 in 8q24 and risk of gastric cancer. Tumour Biol. 2016; 37:299-303.

20. Verhaegh GW, Verkleij L, Vermeulen SH, den Heijer M, Witjes JA, Kiemeney LA. Polymorphisms in the H19 gene and the risk of bladder cancer. Eur Urol. 2008; 54:1118-1126.

21. Moher D, Liberati A, Tetzlaff J, Altman DG. Preferred reporting items for systematic reviews and meta-analyses: the PRISMA statement. BMJ. 2009; 339:b2535.

22. Yang C, Tang R, Ma X, Wang Y, Luo D, Xu Z, Zhu Y, Yang L. Tag SNPs in long non-coding RNA H19 contribute to susceptibility to gastric cancer in the Chinese Han population. Oncotarget. 2015; 6:15311-15320. doi: 10.18632/oncotarget.3840. 
23. Li S, Hua Y, Jin J, Wang H, Du M, Zhu L, Chu H, Zhang Z, Wang M. Association of genetic variants in lncRNA H19 with risk of colorectal cancer in a Chinese population. Oncotarget. 2016; 7:25470-7. doi: 10.18632/ oncotarget.8330.

24. Hua Q, Lv X, Gu X, Chen Y, Chu H, Du M, Gong W, Wang M, Zhang Z. Genetic variants in lncRNA H19 are associated with the risk of bladder cancer in a Chinese population. Mutagenesis. 2016; 31:531-8.

25. Xia Z, Yan R, Duan F, Song C, Wang P, Wang K. Genetic Polymorphisms in Long Noncoding RNA H19 Are Associated With Susceptibility to Breast Cancer in Chinese Population. Medicine (Baltimore). 2016; 95:e2771.

26. Gong WJ, Yin JY, Li XP, Fang C, Xiao D, Zhang W, Zhou HH, Li X, Liu ZQ. Association of well-characterized lung cancer lncRNA polymorphisms with lung cancer susceptibility and platinum-based chemotherapy response. Tumour Biol. 2016; 37:8349-8358.

27. Bhatti P, Doody MM, Alexander BH, Yuenger J, Simon SL, Weinstock RM, Rosenstein M, Stovall M, Abend M, Preston DL, Pharoah P, Struewing JP, Sigurdson AJ. Breast cancer risk polymorphisms and interaction with ionizing radiation among U.S. radiologic technologists. Cancer Epidemiol Biomarkers Prev. 2008; 17:2007-2011.

28. Quaye L, Tyrer J, Ramus SJ, Song H, Wozniak E, DiCioccio RA, McGuire V, Hogdall E, Hogdall C, Blaakaer J, Goode EL, Schildkraut JM, Easton DF, et al. Association between common germline genetic variation in 94 candidate genes or regions and risks of invasive epithelial ovarian cancer. PLoS One. 2009; 4:e5983.

29. Song H, Ramus SJ, Kjaer SK, DiCioccio RA, ChenevixTrench G, Pearce CL, Hogdall E, Whittemore AS, McGuire V, Hogdall C, Blaakaer J, Wu AH, Van Den Berg DJ, et al. Association between invasive ovarian cancer susceptibility and 11 best candidate SNPs from breast cancer genome-wide association study. Hum Mol Genet. 2009; 18:2297-2304.

30. Butt S, Harlid S, Borgquist S, Ivarsson M, Landberg G, Dillner J, Carlson J, Manjer J. Genetic predisposition, parity, age at first childbirth and risk for breast cancer. BMC Res Notes. 2012; 5:414.

31. Barnholtz-Sloan JS, Shetty PB, Guan X, Nyante SJ, Luo J, Brennan DJ, Millikan RC. FGFR2 and other loci identified in genome-wide association studies are associated with breast cancer in African-American and younger women. Carcinogenesis. 2010; 31:1417-1423.

32. Schmitz SU, Grote P, Herrmann BG. Mechanisms of long noncoding RNA function in development and disease. Cell Mol Life Sci. 2016; 73:2491-509.

33. Devaux Y, Zangrando J, Schroen B, Creemers EE, Pedrazzini T, Chang CP, Dorn GW 2nd, Thum T,
Heymans S. Long noncoding RNAs in cardiac development and ageing. Nat Rev Cardiol. 2015; 12:415-425.

34. Pan W, Liu L, Wei J, Ge Y, Zhang J, Chen H, Zhou L, Yuan Q, Zhou C, Yang M. A functional lncRNA HOTAIR genetic variant contributes to gastric cancer susceptibility. Mol Carcinog. 2016; 55:90-96.

35. Yang F, Xue X, Bi J, Zheng L, Zhi K, Gu Y, Fang G. Long noncoding RNA CCAT1, which could be activated by c-Myc, promotes the progression of gastric carcinoma. J Cancer Res Clin Oncol. 2013; 139:437-445.

36. Gabory A, Jammes H, Dandolo L. The H19 locus: role of an imprinted non-coding RNA in growth and development. Bioessays. 2010; 32:473-480.

37. Han D, Gao X, Wang M, Qiao Y, Xu Y, Yang J, Dong N, He J, Sun Q, Lv G, Xu C, Tao J, Ma N. Long noncoding RNA H19 indicates a poor prognosis of colorectal cancer and promotes tumor growth by recruiting and binding to eIF4A3. Oncotarget. 2016; 7:22159-22173. doi: 10.18632/ oncotarget.8063.

38. Shen K, Tseng GC. Meta-analysis for pathway enrichment analysis when combining multiple genomic studies. Bioinformatics. 2010; 26:1316-1323.

39. Lu Y, Tan L, Shen N, Peng J, Wang C, Zhu Y, Wang X. Association of lncRNA H19 rs217727 polymorphism and cancer risk in the Chinese population: a meta-analysis. Oncotarget. 2016; 7:59580-59588. doi: 10.18632/ oncotarget.10936.

40. Chu M, Yuan W, Wu S, Wang Z, Mao L, Tian T, Lu Y, Zhu B, Yang Y, Wang B, Gao H, Jiang L, Zhuang X. Quantitative assessment of polymorphisms in H19 lncRNA and cancer risk: a meta-analysis of 13,392 cases and 18,893 controls. Oncotarget. 2016; 7:78631-78639. doi: 10.18632/ oncotarget.12530.

41. Huedo-Medina TB, Sanchez-Meca J, Marin-Martinez F, Botella J. Assessing heterogeneity in meta-analysis: Q statistic or I2 index? Psychol Methods. 2006; 11:193-206.

42. Mantel N, Haenszel W. Statistical aspects of the analysis of data from retrospective studies of disease. J Natl Cancer Inst. 1959; 22:719-748.

43. DerSimonian R. Meta-analysis in the design and monitoring of clinical trials. Stat Med. 1996; 15:1237-1248.

44. Higgins JP, Thompson SG. Quantifying heterogeneity in a meta-analysis. Stat Med. 2002; 21:1539-1558.

45. Egger M, Davey Smith G, Schneider M, Minder C. Bias in meta-analysis detected by a simple, graphical test. BMJ. 1997; 315:629-634.

46. Begg CB, Mazumdar M. Operating characteristics of a rank correlation test for publication bias. Biometrics. 1994; 50:1088-1101. 